Elsevier

\title{
Effects of carbon monoxide on cochlear electrophysiology and blood flow
}

\author{
Laurence D. Fechter ${ }^{1}$, Peter R. Thorne ${ }^{2}$ and Alfred L. Nuttall ${ }^{2}$ \\ 1 Depts. of Environmental Health Sciences and Otolaryngology Head \& Neck Surgery, Johns Hopkins University Medical Institutions, \\ Baltimore, Maryland, and ${ }^{2}$ Kresge Hearing Research Institute, The University of Michigan Medical School, \\ Ann Arbor, Michigan, U.S.A.
}

(Received 18 July 1986; accepted 15 December 1986)

\begin{abstract}
The belief that the cochlea is particularly vulnerable to a reduction in oxygen availability comes predominantly from studies reporting the disruption of electrophysiological measures, such as the compound action potential, endocochlear potential, inner hair cell intracellular potentials or afferent nerve fiber responses by asphyxiation. Because hypoxia has frequently been suggested as an underlying mechanism by which many ototoxic agents produce injury, and because such agents are not likely to completely disrupt oxygen delivery, we investigated the effects of graded hypoxia (using doses of carbon monoxide) on cochlear blood flow, the compound action potential (CAP) and the cochlear microphonic (CM). High doses of carbon monoxide injected intra-peritoneally yielded reversible loss of the CAP sensitivity for high frequency tone bursts, the extent of which was dose dependent. The loss was observed first at the highest frequency tested $(50 \mathrm{kHz})$ and as carboxyhemoglobin levels increased, contiguous lower frequencies were influenced. Recovery progressed from low to high frequencies as carboxyhemoglobin levels declined. Carbon monoxide administration also produced a dose dependent elevation in the cochlear blood flow measured by a laser Doppler flow monitor. The data suggest that carbon monoxide administration disrupts cochlear function only under extremely severe exposure conditions. An elevation in cochlear blood flow may well serve as a protective mechanism which maintains cochlear function in the face of declining blood oxygen carrying capacity and delivery. While the site of action of carbon monoxide in the cochlea is uncertain, the data clearly indicate that elements involved in the generation of the CAP for high frequency tones are particularly vulnerable. This suggests that such elements may have different metabolic requirements from other lower frequency regions of the cochlea and/or that oxygen delivery (blood circulation) differs in the basal portion of the cochlea.
\end{abstract}

Carbon monoxide hypoxia; Cochlear microphonic; Compound action potential; Cochlear blood flow; Ototoxicity; Laser Doppler

\section{Introduction}

There is a significant historical interest in the role that reduced oxidative metabolism might play in cochlear dysfunction resulting from stress and disease, and also exposure to specific ototoxic agents. Several reports have suggested that ototoxic drugs such as quinine (Hawkins, 1967; Lawrence, 1970; Smith et al., 1985) and salicylates (Hawkins, 1973, 1976) might induce vasoconstriction in the cochlea and that impaired oxygenation might account for the transitory functional loss produced by such agents. Similarly there are reports

Correspondence to: L.D. Fechter, The Johns Hopkins University, School of Hygiene and Public Health, 615 North Wolfe Street, Baltimore, MD 21205, U.S.A. showing that intense sound exposure produces a transitory drop in endolymph oxygen tension (Misrahy et al., 1958; Maass et al., 1976) and that more protracted noise exposures are associated with partial occlusion of the spiral vessel of the basilar membrane (Hawkins, 1971) and stria vascularis (Johnsson and Hawkins, 1972). A number of more recent studies have shown significant changes in the cochlear vasculature following noise exposure that would be suggestive of a decline in blood flow (e.g., Axelsson et al., 1983; Dengerink et al., 1985). However, contradictory findings have also been reported (Hulcrantz, 1979; Nuttall et al., 1981; Prazma et al., 1983).

If depressed cochlear blood flow or reduced oxygen delivery is the mechanism of ototoxicity produced by these diverse agents, then experimen- 
tal manipulations which directly limit oxygen delivery even to a moderate degree should cause cochlear dysfunction. However, much of the data has been derived from experiments using acute asphyxiation and little is known about cochlear function under less severe hypoxic exposure. Asphyxiation results in an almost immediate drop in scala media oxygen tension accompanied by a fall of the endocochlear potential (EP) and cochlear microphonic (CM) (Konishi et al., 1964; Lawrence et al., 1975). The compound action potential (CAP) appears to be particularly sensitive undergoing a precipitous drop in amplitude following asphyxiation (Misrahy et al., 1958) and shows both the largest reduction in amplitude and also the longest time to recovery when compared either to CM or EP (Brown et al., 1983).

There appears to be a close correspondence between the fall in EP and scala media oxygen tension (Nuttall and Lawrence, 1980). During hypoxia EP and intracochlear oxygen tensions begin to fall when inspired oxygen levels reach $16 \%$ and then tend to follow similar decay functions as hypoxia becomes more extreme. The initial delay in response to hypoxic challenge as well as the rebound and overshoot in oxygen tension and EP during the reestablishment of normoxia (Misrahy et al., 1958; Nuttall and Lawrence, 1980; Prazma, 1982) might represent compensatory cardiovascular responses to hypoxia. Finally, there appears to be close correspondence between decrements in CM and EP under conditions of asphyxia (Misrahy et al., 1958; Konishi et al., 1961; Brown et al., 1983) which might be predicted from the variable resistor model of hair cell function suggested by Davis (1965).

In addition to disruption in the primary extracellular $A C$ and $D C$ potentials measurable in the cochlea, altered inner hair cell function has also been observed during asphyxia. Indeed, the principal locus of insult responsible for the drop in CAP appears to be the performance of inner hair cells; a loss in frequency tuning curve tip sensitivity and sharpness of tuning as well as shifts in resting potentials have been described (Russell and Cowley, 1983; Brown et al., 1983; Nuttall, 1984). However, the direct effect of acute hypoxia on the afferent nerve remains unknown.

The experiments reported in the present study were designed to assess the effects of a broad range of hypoxic exposures produced by carbon monoxide administration on pure tone CAP thresholds, CM and cochlear blood flow. Carbon monoxide exposure, like hypoxic hypoxia, is known to produce a profound hearing loss following acute intoxications (Sato, 1966; Morris, 1969; Goto et al., 1972; Makishima et al., 1977). Epidemiological data suggest that chronic, low level exposures also yield hearing loss (Lumio, 1948; Zelman, 1973). Paradoxically, a series of chronic and acute carbon monoxide exposure studies failed to produce shifts in auditory thresholds measured in rats and guinea pigs (Young and Fechter, unpublished). Since carbon monoxide can enhance brain blood flow and thereby maintain higher oxygen delivery than might be predicted purely from carboxyhemoglobin levels (Traystman and Fitzgerald, 1977; Traystman, 1977), we sought to determine whether such a mechanism might also protect the cochlea during hypoxia. In the experiments described in this report, electrophysiologic measures of cochlear function, namely the CAP and $C M$ recorded from the round window, were made along with simultaneous measurement of cochlear blood flow and of oxy- and carboxy-hemoglobin. The results indicate that cochlear blood flow is elevated over a broad range of carboxy hemoglobin levels and that selective disruption of the compound action potential to high frequency tones occurs only under conditions of profound carbon monoxide intoxication.

\section{Materials and Methods}

Male Long Evans rats weighing 300-400 g were used. Subjects were housed in groups with free access to food and water. Prior to surgery, rats were anesthetized by i.m. injections of ketamine $(87 \mathrm{mg} / \mathrm{kg})$ and xylazine $(13 \mathrm{mg} / \mathrm{kg})$. Subjects were tracheotomized, but did not require artificial respiration. Normal body temperature $\left(37 \pm 1^{\circ} \mathrm{C}\right)$ was maintained by a DC heating pad controlled by a rectal probe. The carotid artery contralateral to the tested ear was cannulated using PE50 tubing inserted approximately to the level of the clavicle so that blood pressure could be continuously monitored and periodic blood samples taken for blood gas analysis. The cannula was thor- 
oughly flushed and the heparinized saline discarded so that a fresh blood sample was always taken for blood gas analysis. Two experimental series were performed. In the first, the CAP and $\mathrm{CM}$ were measured in five rats prior to carbon monoxide administration and again at half-hour intervals following a large dose of carbon monoxide. Electrophysiological data were also gathered from three uninjected control subjects whose thresholds were determined at half-hourly intervals. Blood gas analyses using a IL282 CO-oximeter were conducted following each threshold determination so that deficits could be related to oxyhemoglobin and carboxyhemoglobin levels. Based upon these experiments, which did indicate that carbon monoxide produced a transient elevation in threshold for eliciting the CAP at high frequencies, a series of 22 experiments were conducted in which cochlear blood flow as well as CAP, CM and blood gases were monitored prior to and repeatedly following carbon monoxide exposure. Blood flow measurements were performed using a Med Pacific (LD 5000) laser Doppler flow monitor which detects the movement of particles (e.g. red blood cells) in a region of the tissue near the measuring probe. Doppler frequency shift of the laser light scattered within the tissue and reflected back to the probe represents the mean velocity of the moving cells. The total number of moving cells is also part of this measurement. This method provides a dynamic measure of blood flux (Bonner and Nossal, 1981) and has been successfully applied previously for the inner ear (Goodwin et al., 1984; Miller et al., 1983, 1984; Thorne and Nuttall, 1987). Laser Doppler flow measurements for the cochlea currently provide relative measurement of blood flow. Given the thickness of the rat cochlea, it is reasonable to assume that both modiolar and lateral wall blood flow contributed to the measurements reported here as the probe may detect red cells moving in a tissue of $0.6 \mathrm{~mm}^{3}$ (Nilsson et al., 1980).

The auditory bulla was exposed during surgery by a ventral postauricular approach. The bulla was opened near the styloid process using a dental burr and the opening enlarged by carefully shaving the edges of the bony opening so that a silver wire recording electrode could be placed on the round window. The electrode was a teflon in- sulated 40 gauge silver wire and was cemented to the bulla using dental acrylic in order to hold its position on the round window. The CAP and CM signals were preamplified with a gain of $1000 \times$ before analysis. $\mathrm{An} \mathrm{Ag} / \mathrm{AgCl}$ reference electrode was placed in the muscles of the neck. For measuring cochlear blood flow, the probe $(1.7 \mathrm{~mm}$ OD) of a Med-Pacific laser Doppler flow meter was held in a micromanipulator and positioned over the second turn of the rat cochlea. The laser Doppler flow meter was zeroed and the extent of drift checked at the end of each experiment. Drift by the end of the experiment never amounted to more than $+10 \mathrm{mV}$ which would correspond to approximately $2-4 \%$ of the flow readings from the cochlea. The CAP was obtained by presenting acoustic signals consisting of $10 \mathrm{~ms}$ tone bursts at 12 frequencies between 4 and $50 \mathrm{kHz}$. The tone bursts had rise-fall times of $1 \mathrm{~ms}$ and were delivered from a $1 / 2$ inch Brüel \& Kjaer microphone using a closed field sound speculum fitted into the external auditory meatus after removal of the pinna. Tone burst intensities were calibrated using a $1 / 2$ inch recording microphone attached to a $1 \mathrm{~mm}$ probe tube within the speculum which was positioned close to the tympanic membrane. The intensity of $10 \mathrm{~ms}$ tone bursts was varied until the $\mathrm{N}_{1}$ wave of the CAP was just visually detectable on an oscilloscope. The CAP signals were band-pass filtered $30 \mathrm{~Hz}$ to $3 \mathrm{kHz}$ and the visual detection threshold was an $\mathrm{N}_{1}$ of approximately 10 UV. The CM isopotential ( $1 \mathrm{mV}$ RMS) sensitivity functions were obtained for continuous pure tones using a wave analyzer.

Once the CM and CAP had been measured under normoxic conditions, subjects received 1-4 $\mathrm{ml}$ of pure carbon monoxide gas per $100 \mathrm{~g}$ body wt by intra-peritoneal injection. Injected carbon monoxide gas is readily taken up across capillary beds of the peritoneum and binds to hemoglobin with an affinity roughly 210 times that of oxygen (Sendroy and O'Neal, 1955). Tissue hypoxia results both from the actual decrease in oxygen carrying capacity of hemoglobin and from impaired oxygen dissociation from hemoglobin (the Haldane effect) in the presence of carboxyhemoglobin (Roughton and Darling, 1944). A particularly important advantage of the intraperitoneal route of administration is that it eliminated 
the need for chemical exhaust of carbon monoxide gas. In addition, i.p. administration of carbon monoxide produced a rapid elevation in carboxyhemoglobin reaching peak levels at $30-60 \mathrm{~min}$ and remaining steady for an additional 60-120 min. This method of administering carbon monoxide has previously been used in toxicological investigations (Fountain et al., 1986) and has been shown to produce similar neurobiologic consequences to carbon monoxide given by inhalation. Cochlear blood flow, skin blood flow and blood pressure were monitored constantly. The CAP and $\mathrm{CM}$ were determined at $30 \mathrm{~min}$ intervals and 0.3 $\mathrm{ml}$ aliquots of arterial blood were taken for determination of oxyhemoglobin $\left(\mathrm{HbO}_{2}\right)$, carboxyhemoglobin, (HbCO), methemoglobin (HbMet) and oxygen content $\left(\mathrm{Vol} \% \mathrm{O}_{2}\right)$. Blood was replaced with heparinized saline. Control subjects $(n=5)$ were treated identically except that they did not receive a gas injection.

\section{Results}

The initial experiments demonstrated that injection of carbon monoxide resulting in very high carboxyhemoglobin levels $(\bar{x}=56 \%)$ produces a temporary and frequency specific disruption of the compound action potential. The group data, presented in Fig. 1, show audiometric curves for

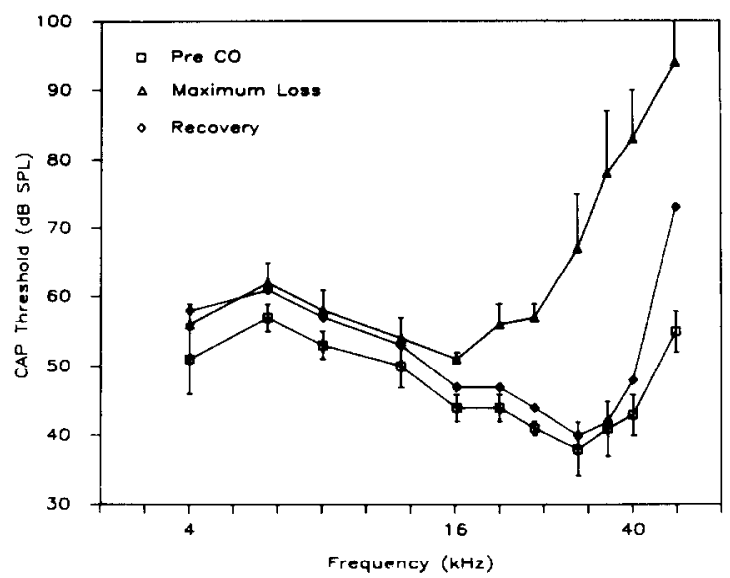

Fig. 1. Compound action potential thresholds (mean \pm S.E.) in five subjects prior to carbon monoxide exposure (squares), at the time of maximal auditory loss following carbon monoxide injection (triangles), and at the end of the experiment (diamonds). the CAP obtained prior to carbon monoxide, at the time of maximal threshold shift (which typically occurred 30-60 min after carbon monoxide exposure) and at termination of the experiment which occurred 120-240 $\mathrm{min}$ after the carbon monoxide injection. Following carbon monoxide injection all subjects exhibited a threshold shift which began at the higher frequencies $(40-50 \mathrm{kHz})$, but gradually extended to affect all test frequencies above $20 \mathrm{kIIz}$. Conversely, recovery of thresholds occurred first at the lowest frequencies that were affected initially. This recovery generally became noticeable (10 $\mathrm{dB}$ improvement at two adjacent frequencies) 90-150 min following carbon monoxide injection. In several subjects recovery of thresholds at the highest frequency tested, $50 \mathrm{kHz}$, was incomplete. Threshold shifts of $4 \pm 3 \mathrm{~dB}$ were observed in untreated control subjects at the time of maximal threshold shift in carbon monoxide treated subjects. A repeated measures analysis of variance confirmed that carbon monoxide exposure significantly disrupted the CAP ( $F=19.37$, $P<0.02$ ). The preferential high frequency disruption is demonstrated by a significant frequency by treatment interaction $(F=8.66, \quad P<0.0001)$. A separate ANOVA comparing CAP sensitivity at the time of maximal threshold shift and at the termination of the experiment failed to demonstrate an overall difference in CAP threshold between these two time points $(F=7.66, P>0.05)$ although a significant frequency by time point interaction was found ( $F=8.40, P<0.0001$ ).

Fig. 2 provides data on the $\mathrm{CM}$ in the same subjects and at the same time intervals as those shown in Fig. 1. The data suggest a modest disruption in high frequency sensitivity and substantial variability among the carbon monoxide-treated subjects. While disruption in CM sensitivity was not sufficiently robust to yield an overall treatment effect $(F=6.51, P>0.05)$ a significant treatment by frequency interaction $(F=3.18, P<$ 0.005 ) indicated reliable loss in $\mathrm{CM}$ sensitivity in subjects following carbon monoxide exposure at high frequencies. A weak residual distuption in high frequency $\mathrm{CM}$ sensitivity remained even at the conclusion of the experiment ( $F=2.22, P<$ 0.05 ). That a loss in $C M$ sensitivity occurs only with extreme carbon monoxide exposure is reflected by the results of eleven subsequent experi- 


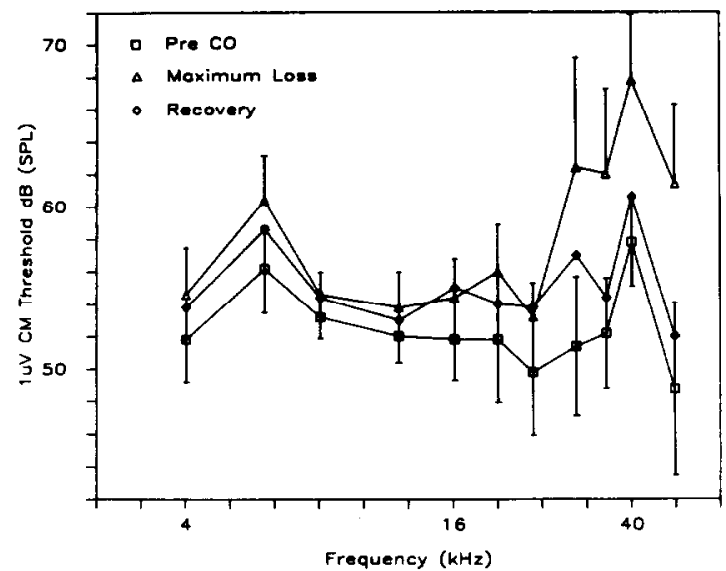

Fig. 2. Cochlear microphonic sensitivity functions (1 UV) (mean \pm S.E.) in five subjects prior to carbon monoxide exposure (squares), at the time of maximal auditory loss following carbon monoxide injection (triangles) and at the end of the experiment (diamonds).

ments carried out under less severe carbon monoxide hypoxia. While significant loss of CAP sensitivity occurred in all cases, only three also showed a loss of CM sensitivity of $10 \mathrm{~dB}$ or greater. And in each of these three cases, the shift in CAP was far larger in magnitude and number of frequencies affected than for CM. Among control subjects there was a CM threshold shift of $2 \pm 6 \mathrm{~dB}$ at the time equivalent to that which produced the most extreme shift in carbon monoxide treated subjects.

By injecting subjects with different amounts of carbon monoxide gas (1-4 ml CO per $100 \mathrm{~g}$ body wt) it was possible to vary the peak $\mathrm{HbCO}$ level obtained. Fig. 3 presents data relating the mean CAP threshold shift at three selected tone frequencies to $\mathrm{HbCO}$ levels measured at each test interval. It is apparent, first, that carbon monoxide-induced threshold shifts follow a rather steep dose-response curve with only modest high frequency threshold elevation seen below 50\% $\mathrm{HbCO}$ and very large shifts in high frequency CAP responses seen with higher $\mathrm{HbCO}$ values. The CAP evoked by mid-frequency tones ( 20 and $24 \mathrm{kHz}$ ) was affected only in those subjects receiving the highest carbon monoxide doses. The time course for $\mathrm{HbCO}$ elevation and elimination in those subjects which did and those which did not show a threshold shift (threshold shift being de-

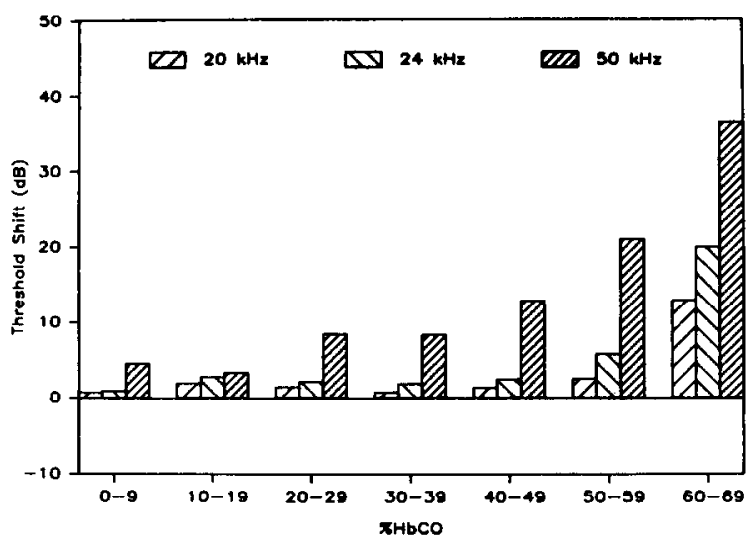

Fig. 3. Compound action potential threshold loss at $20 \mathrm{kHz}, 24$ $\mathrm{kHz}$ and $50 \mathrm{kHz}$ as a function of carboxyhemoglobin $(\mathrm{HbCO})$ level.

fined as loss in CAP sensitivity of at least $10 \mathrm{~dB}$ at two adjacent frequencies) is shown in Fig. 4. These data show a rapid build-up in $\mathrm{HbCO}$ reaching a peak at about $60 \mathrm{~min}$ : a time which corresponds well with the time of maximal threshold shift of the CAP. A comparison between the slopes of carboxyhemoglobin elevation and recovery did not significantly differ between subjects showing a loss in CAP threshold and those which failed to show such a threshold shift $(t=-0.848, P>0.1)$.

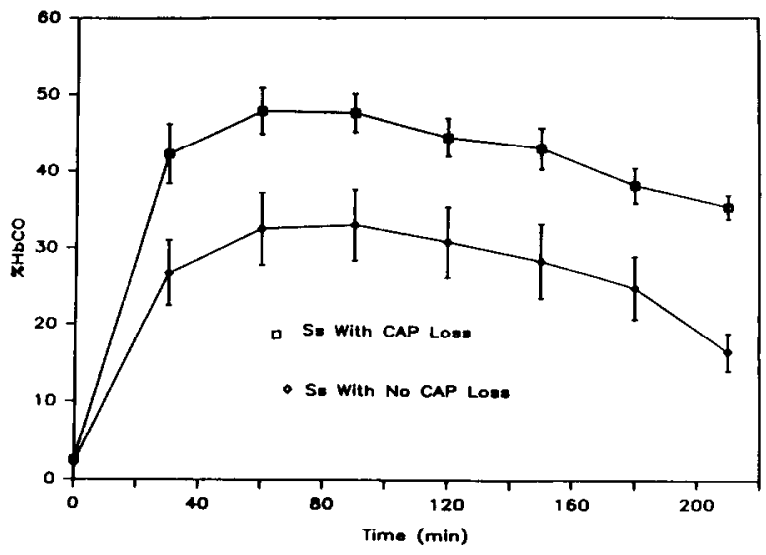

Fig. 4. Pattern of carboxyhemoglobin formation (mean \pm S.E.) and elimination in subjects demonstrating at least a $10 \mathrm{~dB}$ loss in compound action potential threshold at two adjacent frequencies (squares) and subjects not demonstrating a shift in compound action potential thresholds (diamonds). 
However, average carboxyhemoglobin levels were significantly higher among subjects showing a threshold shift $(t=2.28, P<0.025)$. In all but 2 cases subjects not showing a loss in CAP sensitivity had carboxyhemoglobin levels below $40 \%$.

Cochlear blood flow is significantly elevated in subjects injected with carbon monoxide (Fig. 5). This increased flow closely parallels the time course of carboxyhemoglobin elevation and is correlated significantly with rising carboxyhemoglobin level $(r=0.78)$ (Fig. 6). However, while cochlear blood flow and carboxyhemoglobin levels are both higher among carbon monoxide subjects showing a $10 \mathrm{~dB}$ or greater loss in CAP threshold at two adjacent frequencies than those not showing such a loss, there is considerable overlap between cochlear blood flow levels for these groups. In fact, repeated ANOVA measures while finding a significant overall shift in cochlear blood flow over time $(F=3.85, \quad P<0.0001)$ failed to distinguish between the blood flow changes of the two groups of subjects $(F=1.03, P>0.4)$. Such data suggest a possible upper limit on the extent of cochlear blood flow elevation induced by carbon monoxide exposure. Because cochlear blood flow might be expected to vary with blood pressure, particular attention was devoted to the relation-

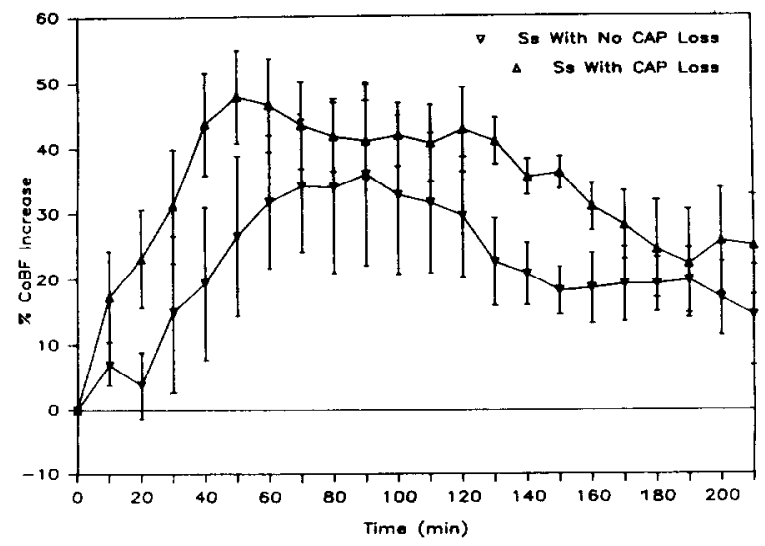

Fig. 5. Percent elevation in cochlear blood flow level relative to pre-carbon monoxide exposure period in subjects demonstrating at least a $10 \mathrm{~dB}$ loss in compound action potential threshold at two adjacent frequencies (triangles) and subjects not demonstrating a shift in compound action potential thresholds (inverted triangles).

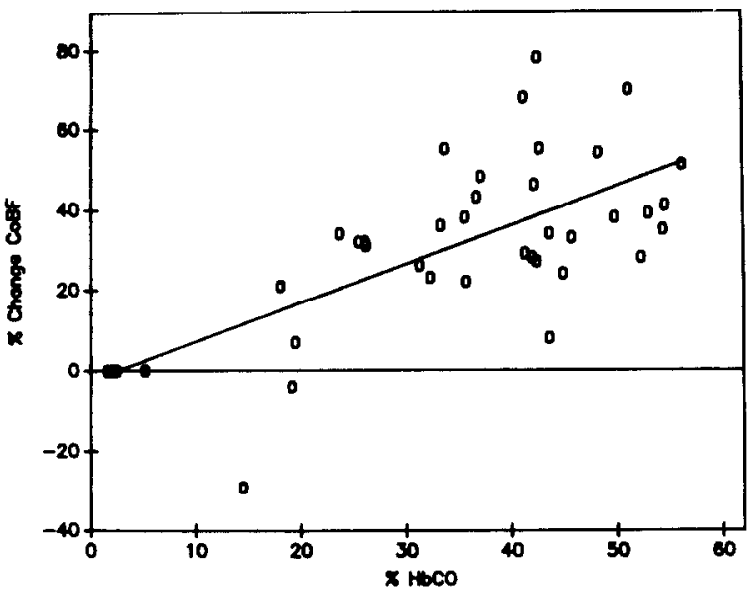

Fig. 6. Relationship between elevation in cochlear blood flow relative to pre-carbon monoxide exposure period and carboxyhemoglobin level following exposure.

ship between the measures in control and CO-injected subjects.

Among control rats, blood pressure fell from $83 \pm 3$ to $68 \pm 2 \mathrm{mmHg}$ over the $4 \mathrm{~h}$ of experimentation; a shift of slightly less than $20 \%$. Cochlear blood flow fell slightly less dramatically (8\%) in these subjects over the same time period. A correlation coefficient of 0.60 was calculated between cochlear blood flow and blood pressure. Among rats treated with $\mathrm{CO}$ and showing significant declines in CAP sensitivity, blood flow declined from $82 \pm 3$ to $60 \pm 4$ over the $4 \mathrm{~h}$ experiment; a $25 \%$ decline. The drop in blood pressure was cssentially linear over time at $0.7 \mathrm{mmHg}$ per $10 \mathrm{~min}$. Cochlear blood flow, as depicted in Fig. 5 was poorly correlated with blood pressure $(r=0.07)$.

\section{Discussion}

Experiments reported here have demonstrated a frequency selective influence of carbon monoxide administration on the CAP. There is a small effect of carbon monoxide administration on $\mathrm{CM}$ generated by high frequency tones (under the present exposure and measurement conditions), and an apparent insensitivity of the CAP to all but the very severest hypoxic condition. The last finding may relate to the clear dose-related elevation in cochlear blood flow elicited by carbon monoxide 
exposure. Such findings require a decidedly different interpretation of cochlear vulnerability to hypoxia than the results of experiments in which tracheal clamping or $100 \% \mathrm{~N}_{2}$ are used in producing anoxia. In the current work we demonstrate a large, dose-related elevation in cochlear blood flow following carbon monoxide exposure. Such a hemodynamic change would tend to ameliorate tissue hypoxia in the face of even large impairments of oxygen carrying capacity and may well be responsible for the ability of the cochlea to maintain normal function even with high carboxyhemoglobin levels.

To the extent that cochlear blood flow is an important determinant of cochlear function, it might be anticipated that carbon monoxide exposure will disrupt cochlear function only if this adaptive mechanism is unable to sustain cochlear oxygen delivery. Previous studies have shown that brain blood flow increases stoichiometrically with increments in inspired carbon monoxide concentration or decrements in inspired oxygen resulting from inhalation of air mixed with differing nitrogen concentrations (Traystman and Fitzgerald, 1977; Traystman, 1977). Because the cochlea is supplied by the anterior inferior cerebellar artery, we suspect our measurement of an increase in cochlear blood flow may parallel an overall increase in brain blood flow. That active processes are involved in determining cochlear blood flow are suggested by the relationship found between blood pressure and cochlear blood flow. While under normal conditions (i.c. in control subjects) some relationship was found between these measures only $36 \%$ of the variability in flow can be accounted for by blood flow. When placed under hypoxic stress, by contrast, there is no statistical relationship between blood pressure and cochlear blood flow and other active processes must be responsible for the elevation in flow levels which were observed. Experiments which have used a range of non-lethal hypoxic exposures may provide the opportunity to observe dynamic changes in cochlear blood flow with attendent electrophysiological effects while asphyxiation produced either by tracheal clamping or inhalation of $100 \%$ nitrogen may mask the cardiovascular responses which are capable of sustaining cochlear function. In evaluating vulnerability of cochlear function to hypoxia, then, it may also be necessary to determine whether compensatory cardiovascular responses are eliminated.

The production of profound, but comparatively gradual hypoxia induced by carbon monoxide injection also provides new data concerning the dynamic nature of cochlear impairment once carboxyhemoglobin levels exceed critical levels. While the current data are consistent with earlier studies in showing a greater impairment of the CAP than CM under hypoxia, the results of the present work show a preferential disruption of the CAP in response to high frequency tones rather than a threshold shift for all test frequencies. Generally asphyxiation experiments have not been able to provide the same extent of frequency data as that obtained here under comparatively extended, stable hypoxic insults. Whether this result reflects differences in the amount of blood supplying the basal and more apical turns of the cochlea or differences in metabolic activity of cells at the basal end of the cochlea or both remains to be determined. It is particularly interesting that the CAP evoked by high frequency tones is preferentially impaired, however, since there is some evidence that the basal turn may be able to receive oxygen by diffusion across the round window in addition to that delivered by blood (Morgenstern and Kessler, 1978; Maass et al., 1976). It seems unlikely that outgassing of carbon monoxide from blood and diffusion across the round window would occur given the very high affinity of hemoglobin for carbon monoxide in blood even when this gas is delivered by inhalation. Rather, one might expect basal turn oxygen levels to be slightly elevated relative to more apical turns even in the experimental subjects used here. Clearly, however, such an oxygen gradient, if it exists, is incapable of sustaining cochlear function under the present conditions. The current data may be more consistent with the notion that function in the basal turn of the cochlea has higher energy requirements than at more apical levels.

The current data showing that the CAP is particularly disrupted under severe carbon monoxide exposure are consistent with the reported outcome of anoxia experiments where CM has been shown to be either less affected by or more resistent to anoxia or chemical asphyxiation than is the CAP 
(Misrahy et al., 1958; Konishi and Kelsey, 1968; Brown et al., 1983). These results appear to be inconsistent with those of Pierson and Moller (1982) who reported that hypoxia depressed the $\mathrm{CM}$ associated with outer hair cells while actually increasing the amplitude of the CAP at low tone intensities. However, in that study hypoxia was produced by decreasing ventilation rate by about $40 \%$ and $\mathrm{CM}$ was recorded from the second turn using differential intracochlear electrodes. These methodological differences make it difficult to draw direct comparisons to our study. By reducing ventilation rate, Pierson and Møller (1982) probably elevated arterial $\mathrm{PCO}_{2}$ and this could be expected to increase cochlear blood flow although it is not possible to estimate the magnitude of such an effect. Given changes in cochlear blood flow and in oxygen dissociation under hypercapnia it is possible that the increased $N_{1}$ amplitude observed by Pierson and Møller (1982) could actually reflect enhanced oxygen delivery to the cochlea.

\section{Acknowledgements}

The authors wish to acknowledge the skillful technical assistance of Nadine Brown and Michelle Griffiths in conducting these experiments, of the ECMO laboratory and staff at the University of Michigan Medical Center for providing access to their blood gas analysis lab and to Professor Joseph Hawkins, Jr. for his helpful comments on an earlier draft of this manuscript. This work was supported in part by PHS grants ES-02852, RCDA ES-00125 for L.F., USPHS International Research Fellowship TW03473 for P.T., and NIH NS11731 for A.N.

\section{References}

Axelsson, A., Borg, E. and Hornstrand, C. (1983) Noise effects on the cochlear vasculature in normotensive and spontaneously hypertensive rats. Acta Oto-Laryngol. 96, 215-225.

Bonner, R. and Nossal, R. (1981) Model for laser Doppler measurements of blood flow in tissue. Appl. Optics 20, 2097-2107.

Brown, M.C., Nuttall, A.L., Masta, R.l. and Lawrence, M. (1983) Cochlear inner hair cells: Effects of transient asphyxia on intracellular potentials. Hear. Res. 9, 131 144.

Davis, H. (1965) A model for transducer action in the cochlear. Cold Spring Harbor Symp. Quant. Biol. 30, 181-191.
Dengerink, H., Miller, J., Axelsson, A., Vertes, D. and Van Dalfsen, P. (1985) The recovery of vascular changes following brief noise exposure. Acta Oto-Laryngol. 100, 19-25.

Fountain, S., Raffaele, K. and Annau, Z. (1986) Behavioral consequences of intraperitoneal carbon monoxide administration in rats. Toxicol. Appl. Pharmacol. 83, 546-555.

Goodwin, P.C., Miller, J.M., Dengerink, H.A., Wright, J.W. and Axelsson, A. (1984) The laser Doppler: A non invasive measure of cochlear blood flow. Acta Oto-Laryngol. 84, $403-412$.

Goto, I., Miyoshi, T. and Yoshitomo, O. (1972) Deafness and peripheral neuropathy following carbon monoxide intoxication. Fol. Psychiat. Neurol, Jap. 26, 35-38.

Hawkins, J.E. (1967) Iatrogenic toxic deafness in children. In: Deafness in Childhood. Editors: F. McConnell and P. Ward. Vanderbilt University Press, Nashville.

Hawkins, J.E. (1971) The role of vasoconstriction in noise-induced hearing loss. Ann. Otol. Rhinol. Laryngol. 80, 903-913.

Hawkins, J.E. (1973) Comparative otopathology: Aging, noise and ototoxic drugs. Ad. Oto-Rhino-Laryngol. 20, 125-141.

Hawkins, J.E. (1976) Drug Ototoxicity. In: Auditory System: Clinical and Special Topics. Editors: W. Keidel and W. Neff, Springer-Verlag, New York.

Hawkins, J.E., Jr., Johsson, L.-G. and Preston, R.E. (1972) Cochlear microvasculature in normal and damaged ears. Laryngoscope 82, 1091-1104.

Hultcrantz, E. (1979) The effect of noise on cochlear blood flow in the conscious rabbit. Acta Physiol. Scand. 106, $29-37$.

Johnsson, L.-G. and Hawkins, J. (1972) Strial atrophy in clinical and experimental deafness. J. Laryngol. 82, 1105-1125.

Konishi, T. and Kelsey, E. (1968) Effect of cyanide on cochlear potentials. Acta Oto-Laryngol. 65, 381-399.

Konishi, T., Butler, R. and Fernandez, C. (1961) Effect of anoxia on cochlear potentials. J. Acoust. Soc. Am. 33, $349-356$.

Lawrence, M. (1970) Circulation in the capillaries of the basilar membrane. Laryngoscope 80, 1364-1375.

Lawrence, M., Nuttall, A.L. and Burgio, P.A. (1975) Cochlear potentials and oxygen associated with hypoxia. Ann. Otol. Rhinol. Laryngol. 84, 499-512.

Lumio, J.S. (1948) Hearing deficiencies caused by carbon monoxide (generator gas). Oto-Laryngological Clinic of the University, Helsinki, p. 112.

Maass, B., Baumgartl, H. and Lubbers, D.W. (1976) Lokale $\mathrm{PO}_{2}$ und $\mathrm{pH}_{2}$-messungen mit Nadelelektroden zum Studium der Sauerstoffversorgung und Microzirkulation des Innerohres. Arch. Otol. Rhinol. Laryngol. 214, 109-114.

Makishima, K., Keaner, W., Vernose, G. and Snow, J. (1977) Hearing loss of a central type secondary to carbon monoxide poisoning. Trans. Alm. Acad. Ophthal. Otol. 84, $452-547$.

Miller, J.M., Marks, N.J. and Goodwin, P.C. (1983) Laser Doppler measurements of cochlear blood flow. Hear. Res. 11, 385-394.

Miller, J.M., Goodwin, P.C. and Marks, N.J. (1984) Inner ear 
blood flow measured with a laser Doppler system. Arch. Otolaryngol. 110, 305-308.

Misrahy, G.A., Shinabarger, E.W. and Arnold, J.E. (1958) Changes in cochlear endolymphatic oxygen availability, action potential, and microphonics during and following asphyxia, hypoxia, and exposure to loud sounds. J. Acoust. Soc. Am. 30, 701-704.

Morgenstern, C. and Kessler, M. (1978) Oxygen consumption and oxygen distribution in the inner ear. Arch. Oto-RhinoLaryngol. 220, 159-162.

Morris, T.M.O. (1969) Deafness following acute carbon monoxide poisoning. J. Laryngol. Otol. 83, 1219-1225.

Nilsson, G.E., Tenland, T. and Oberg, P.A. (1980) Evaluation of a laser Doppler flowmeter for measurement of tissue blood flow. IEEE Trans. Biomed. Eng. 27, 597-604.

Nuttall, A.L. (1984) Dynamic aspects of guinea pig inner hair cell receptor potentials with transient asphyxia. Hear. Res. $16,1-16$.

Nuttall, A.L. and Lawrence, M. (1980) Endocochlear potential and scala media oxygen tension during partial anoxia. Am. J. Otol 1, 147-153.

Nuttall, A.L., Hultcrantz, E. and Lawrence, M. (1981) Does loud sound influence intracochlear oxygen tension? Hear. Res. 5, 285-293.

Pierson, M.G. and Møller, A.R. (1982) Corresponding effects of hypoxia on the cochlear mictophonic and the compound action potential. Hear. Res. 6, 83-101.

Prazma, J. (1982) Perilymphatic and endolymphatic $\mathrm{PO}_{2}$ variations during anoxia, hyperoxia and hypercapnia. Arch. Otolaryngol. 108, 539-543.

Prazma, J., Rodgers, G. and Pillsbury, H. (1983) Cochlear blood flow. Arch. Otolaryngol. 109, 611-615.
Roughton, F.J.W. and Darling, R.C. (1944) The effect of carbon monoxide on the oxyhemoglobin dissociation curve. Am. J. Physiol. 141, 17-31.

Russell, IJ. and Cowley, E. (1983) The influence of transient asphyxia on receptor potentials in inner hair cells of the guinea pig cochlear. Hear. Res. 11, 373-384.

Sato, T. (1966) Hearing disturbances in monoxide gas toxicosis. Otolaryngology (Tokyo) 38, 805-816.

Sendroy, J. and O'Neal, J.D. (1955) Affinity constant for carbon monoxide and oxygen in blood. Fed. Proc. 14, 137.

Smith, D.I., Lawrence, M. and Hawkins, J.E. (1985) Effects of noise and quinine on the vessels of the stria vascularis: An image analysis study. Am. J. Otolaryngol. 6, 280-289.

Thorne, P.R. and Nuttall, A.L. (1987) Laser Doppler measurements of cochlear blood flow during loud sound exposure in the guinea pig. Hear. Res. 27, 1-10.

Traystman, R. (1977) Effect of carbon monoxide hypoxia and hypoxic hypoxia on cerebral circulation. In: Neurobehav. ioral Effects of Environmental Stressors, USEPA, pp. 453-458. Editor: D. Otto.

Traystman, R. and Fitzgerald, R. (1977) Cerebral circulatory responses to hypoxic hypoxia and carbon monoxide hypo$x i a$ in carotid baroreceptor and chemoreceptor denervated dogs. Acta Neurol. Scand. 56 (Suppl. 64), 294-295.

Young, J.S., Upchurch, M.B., Kaufman, M.J. and Fechter, L.D. (1987) Carbon monoxide exposure potentiates high frequency threshold shifts induced by noise. Hear. Res. 26 , $37-43$.

Zelman, S. (1973) Correlation of smoking history with hearing loss. JAMA 223, 920. 